NEUROLOGICAL PICTURE

\title{
Cystic dysplasia of the corpus callosum in interhemispheric disconnection syndrome
}

This 29 year old post office clerk had been treated with ventricular drainage at 2 years of age after hydrocephalus was diagnosed. Recently he was admitted with a tension-like headache and dizziness, which could be explained by shunt dysfunction. The patient furthermore reported difficulty in coordinating movements of his limbs-for example, during typing and climbing up a ladder. On examination he presented with difficulty in walking heel to toe and in exchanging sensorimotor information between both hemispheres (for example, alternating bilateral tapping, bilateral coordinated arm rotations, finger sequence repetition). Cranial MRI showed dysplasia of the trunk of the corpus callosum (figure, A and B), with a thin, garland shaped posterior trunk and multiple adjacent cyst-like structures. The spatial relation between corpus callosum and cysts could best be illustrated by three dimensional reconstruction using image postprocessing (figure, C and D). Additional findings were an extraordinarily thick skull and a large premesencephalic arachnoid cyst. The pericallosal cysts were considered to be neuroepithelial in origin and might have hindered the migration of callosal fibres accross the midline during embryogenesis, resulting in interhemispheric disconnection syndrome.

KARL T HOFFMANN

Department of Radiology, Campus Virchow Klinikum, Charité, Humboldt University, Augustenburger Platz 1, D-13353 Berlin, Germany

Department of Neurology

BERND U MEYER

Correspondence to: Dr K T Hoffmann 

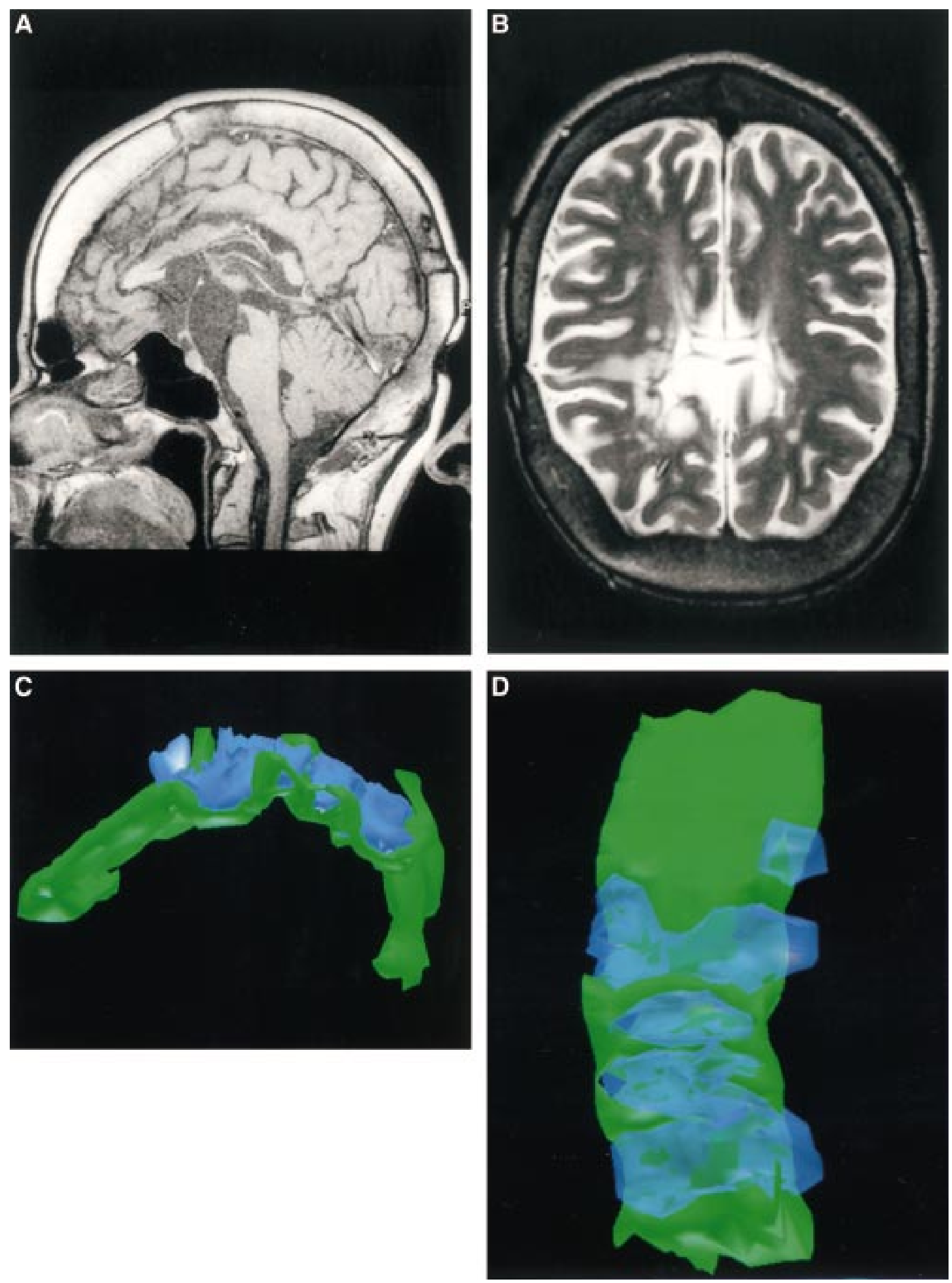

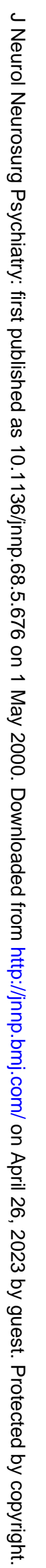

